\title{
ASPECTOS PRAGMÁTICO-LINGÜÍSTICOS DEL DISCURSO DEL TURISMO DE AVENTURA: ESTUDIO DE UN CASO ${ }^{1}$
}

\author{
PRAGMALINGUISTICS FEATURES OF THE ADVENTURE \\ TOURISM DISCOURSE: A CASE STUDY
}

Isabel DuRÁN MuÑOZ

Universidad de Málaga

\section{RESUMEN:}

El objetivo de este trabajo es ofrecer una visión general del discurso turístico con respecto a sus principales características pragmático-lingüísticas y contrastarlo con un subsegmento turístico concreto. En este caso, nos aproximaremos al turismo de aventura, un tipo de turismo que está creciendo exponencialmente en los últimos años y que, por tanto, está ganando importancia en el sector turístico en España. Para ello, analizaremos un corpus de textos promocionales sobre este tipo de turismo a fin de ejemplificar dichas características e ilustrar a los traductores profesionales acerca de las posibles dificultades que puedan encontrar durante la traducción de este tipo de textos al español.

PALABRAS CLAVE: Aspecto pragmático-lingüístico, discurso del turismo, turismo de aventura, texto promocional.

\section{ABSTRACT:}

The aim of this paper is to provide an overview of the tourism discourse regarding their main pragma-linguistic features and compare it with a specific tourism subsegment. In this case, we will approach the adventure tourism, a type of tourism that has been growing exponentially in recent years and, therefore, is gaining importance in the tourism sector in Spain. To do so, we analyse a text corpus consisting of Spanish promotional texts on the adventure tourism in order to exemplify and illustrate these features to professional translators and minimise possible difficulties they may encounter during the translation of such texts into Spanish.

KEYWORDS: Pragmalinguistic feature, tourism discourse, adventure tourism, promotional text.

${ }^{1}$ El presente trabajo ha sido realizado parcialmente en el seno de los proyectos INTELITERM (FFI2012-38881) y TERMITUR (Ref. HUM2754, 2014-2017. Junta de Andalucía). 


\section{INTRODUCCIÓN}

El turismo se define, según la Organización Mundial del Turismo (OMT), como una actividad económica que ofrece servicios a personas que se desplazan fuera de sus lugares habituales de residencia, por un tiempo inferior a un año, con fines de ocio, por negocio o por otros motivos, y no por motivos lucrativos ${ }^{2}$.

Partiendo de esta definición, se puede considerar el turismo como una actividad intercultural e interlingüística que «une» personas, culturas, lenguas y lugares mediante la provisión de servicios y productos turísticos. Esta carga cultural -además de linguísticaque incluye el turismo otorga al discurso turístico una dimensión propia y lo convierte en un lenguaje de mediación, tanto desde un punto de vista lingüístico como cultural. Debido a este carácter interlingüístico e intercultural, la traducción en este ámbito adquiere una posición imprescindible, ya que está presente en todo producto y texto turístico de una zona y sirve de mediación entre los turistas y las personas locales y su cultura.

En nuestra opinión, compartida con autores relevantes de este ámbito (Calvi, 2000, 2010; Kelly, 1997; Dann, 1996), los aspectos léxicos, sintácticos y textuales propios del discurso del turismo lo convierten en un lenguaje de especialidad, con unas características propias y diferentes de otros lenguajes de especialidad y, por tanto, alejado de la lengua general. En este sentido, lenguaje de especialidad (o discurso de especialidad) se considera como un subcódigo de la lengua general que se emplea en una situación comunicativa concreta en la que se transmite conocimiento especializado y que presenta características léxicas, sintácticas, morfológicas y gráficas determinadas que los diferencian de otros discursos especializados. Como expresa Cabré Castellví (2002: 22):

[Los lenguajes especializados se consideran como] productos predominantemente verbales, de registros comunicativos específicos, que tratan temas propios de un ámbito de especialidad, que respetan convenciones y tradiciones retórico-estilísticas y que dan lugar a clases textuales determinadas.

A la hora de distinguirlo de otros lenguajes de especialidad y de la lengua general, tendremos que analizar, por tanto, sus aspectos pragmático-lingüísticos y textuales propios, tales como la función comunicativa en cada situación, los interlocutores (emisor o receptor), la intención y el registro, sin olvidar las características lingüísticas que los determina y los géneros textuales que lo comprenden. En esta misma línea, y siendo el tema que nos ocupa en este trabajo, para tratar la traducción especializada de textos turísticos será necesario conocer de primera mano dichos aspectos, a fin de aproximarse convenientemente al texto original y ofrecer una traducción correcta y adecuada de acuerdo con las indicaciones del encargo y el objetivo de la traducción.

\footnotetext{
${ }^{2}$ Esta definición se aprobó en la Conferencia sobre Estadísticas de Viajes y Turismo celebrada en Otawa en junio de 1991, donde se acordaron una serie de recomendaciones sobre estadísticas de turismo de la OMT.
} 


\section{EL TURISMO Y SUS GÉNEROS TEXTUALES}

Como se ha indicado anteriormente, el discurso del turismo se considera como un lenguaje de especialidad a razón de la existencia de géneros textuales propios y funcionales para sus objetivos comunicativos. Por lo que respecta a la traducción, es imprescindible tener en cuenta la variabilidad de géneros textuales dentro del ámbito turístico y, por tanto, el conocimiento por parte del traductor encargado acerca de los géneros textuales y de sus características propias para que sea capaz de alcanzar buenos resultados en sus traducciones.

Partiendo de una clasificación general de los textos turísticos de cualquier segmento, podemos distinguir dos grupos básicamente: por un lado, los textos turísticos promocionales y, por otro, los textos turísticos no promocionales (Kelly, 1997: 34; Brosson, 2008: 10), aunque realmente la mayoría de los textos turísticos recaen en una categoría intermedia o híbrida que, por su aspecto pragmático-lingüístico, presenta una mezcla de ambos géneros (cfr. Calvi, 2010: 9).

En el primer grupo encontramos los textos turísticos cuyo principal objetivo es la venta de productos y servicios en el lugar de destino y, para ello, emplean un lenguaje directo, breve y persuasivo, lleno de optimismo y de belleza. Entre este tipo de textos destacan los folletos turísticos de ciudades, de museos, de atracciones turísticas, etc.; los catálogos de hoteles, de agencias de viajes, de productos turísticos, etc.; los reportajes y los artículos publicados en revistas no especializadas o de promoción, como revistas de líneas aéreas (Ronda Iberia, en español) o revistas de puertos (Aqua Vista, en español) así como los reportajes en programas de televisión o en radio; los anuncios publicitarios y las páginas web promocionales de diferente naturaleza (directorios, como Rural Ibérica ${ }^{3}$; portales, como la página de Turismo Andaluz ${ }^{4}$; buscadores, como Rutas y Viajes.net ${ }^{5}$, etc.) (Calvi, 2006: 272), todos ellos elaborados por expertos en turismo y dirigidos a un destinatario general que desea información para organizar sus vacaciones o sus visitas en el lugar de destino.

En el segundo grupo, encontramos los textos no promocionales y los «textos operativos para el turista» (Kelly, 1997: 35). En el primer caso, encontramos las guías turísticas, las audio-guías de museos o de otros lugares de interés, los mapas y planos de ciudad, las cartas de los bares y restaurantes, las condiciones generales de cualquier contrato turístico (alojamiento, transporte, viaje combinado, actividad de aventura, seguro turístico, etc.), entre otros ${ }^{6}$. En este subgrupo, también se incluirían los artículos científicos publicados en revistas especializadas como Cuadernos Turísticos (en español),

\footnotetext{
${ }^{3}$ En www.ruraliberica.com.

${ }^{4}$ En www.andalucia.org.

${ }^{5}$ En www.rutasyviajes.net.

${ }^{6}$ A pesar de que estos textos son considerados como textos no promocionales, las guías turísticas, e incluso los mapas, incluyen a menudo un lenguaje similar al de los textos promocionales, en cuanto se refiere a la descripción de lugares, monumentos, etc., puesto que emplean un lenguaje lleno de positivismo, de adjetivos que indican la belleza, la autenticidad, la originalidad de lo que estén describiendo, lo que puede llegar a confundirlos con los textos promocionales. No obstante, su principal función es informativa y, así, su función apelativa no ocupa un lugar preponderante como en el grupo
} anterior. 
International Journal of Tourism y Annals of Tourism Research (en inglés) o Tourismus Journal (en alemán), que no tienen un objetivo promocional, sino científico. Por su parte, los denominados «textos operativos para el turista» hacen referencia a textos producidos por autoridades (aduana, policía, aeropuerto) con objeto de aportar instrucciones, recomendaciones sobre diferentes asuntos relevantes para los turistas. En general, el principal objetivo de estos textos deja de ser prioritariamente de persuasión para imperar el aspecto informativo, bien para informar acerca de la seguridad de los turistas o bien sobre algún aspecto concreto del lugar de destino.

El acceso generalizado a Internet en los últimos años a la hora de buscar información o de contratar productos y servicios turísticos ha dado lugar a nuevas posibilidades de comunicación, con las que, por un lado, los géneros tradicionales se han vuelto más accesibles y, con esto, más persuasivos y con mayor presencia de recursos icónicos, más interactivos y más directos $\mathrm{y}$, por otro, han surgido nuevas formas de comunicación donde los emisores son los mismos turistas que transmiten sus opiniones, recomendaciones, etc. a través de foros de viajeros, blogs, entre otros con una función principalmente informativa (Calvi y Bonomi, 2008: 185; Sanmartín, 2012; Calvi, 2014).

Tanto es así que la última Encuesta de Gasto Turístico (Egatur), que lleva a cabo todos los años el Ministerio de Industria, Energía y Turismo (2013), se indicaba que el $65 \%$ de los turistas internacionales recibidos había hecho uso de Internet para la planificación del viaje, lo que equivale a un $8 \%$ más que en 2011.

\begin{tabular}{|c|c|c|}
\hline & $\begin{array}{l}\text { Porcentaje de } \\
\text { Turistas }\end{array}$ & \begin{tabular}{|c|} 
Tasa de Variación \\
{$[\%]$}
\end{tabular} \\
\hline Total & $100 \%$ & $8 \%$ \\
\hline No usa Internet & $35 \%$ & $-6 \%$ \\
\hline Usa Internet & $65 \%$ & $8 \%$ \\
\hline Consulta & $64 \%$ & $9 \%$ \\
\hline Transporte & $60 \%$ & $8 \%$ \\
\hline Alojami ento & $48 \%$ & $14 \%$ \\
\hline Actividades & $27 \%$ & $11 \%$ \\
\hline Reserva & $59 \%$ & $12 \%$ \\
\hline Transporte & $56 \%$ & $11 \%$ \\
\hline Alojami ento & $43 \%$ & $19 \%$ \\
\hline Actividades & $11 \%$ & $25 \%$ \\
\hline Pago & $56 \%$ & $13 \%$ \\
\hline Transporte & $55 \%$ & $12 \%$ \\
\hline Alojami ento & $34 \%$ & $20 \%$ \\
\hline Actividades & $10 \%$ & $31 \%$ \\
\hline
\end{tabular}

Tabla 1. Uso de Internet por parte de los turistas que visitaron España en 2012.

Fuente:ITE. Encuesta de Gasto Turístico (Egatur) (Ministerio de Industria, Turismo y Comercio, 2013: 45).

Esto explica en gran medida los cambios que se están produciendo en los géneros tradicionales promocionales y el surgimiento de un género nuevo no contemplado hasta hace muy poco tiempo, donde la comunicación se produce de turista a turista, es decir, una comunicación no especializada. Tal y como afirma Dann (2007), este impulso de la 
red y este nuevo género en el discurso turístico acabará menoscabando el papel de los expertos en la transmisión de información: «the traditional guidebook containing printed information about a given place, by its own admission, may well be out-of-date from the very moment it is published» (2007: 15).

Asimismo, debemos tener en cuenta la elevada presencia de textos híbridos o multitextuales (Reiss y Vermeer, 1991) en el ámbito del turismo, esto es, textos que combinan en su estructura varios tipos de texto. De esta manera, un texto turístico, por ejemplo un folleto turístico, puede incluir una poesía, un menú gastronómico, resúmenes históricos y publicidad, todo ello combinado correctamente y de forma clara y precisa. En este sentido, no se puede determinar claramente siempre el género textual en cuestión que se está tratando y que, en su caso, se va a traducir.

Habida cuenta de la variación de géneros textuales que existe en el ámbito turístico, este trabajo se centrará únicamente en el primer grupo, a saber, los textos promocionales, y, a partir de ellos, presentaremos la caracterización de este discurso especializado. A pesar de tratarse de una categoría general de textos turísticos, todos los tipos textuales que se incluyen en ella comparten las mismas características en cuanto a los tres planos analizados: plano lingüístico, plano pragmático y plano funcional, aunque varían en cuanto al formato de presentación y la longitud de los textos que lo forman.

\section{ASPECTOS PRAGMÁTICO-LINGÜÍSTICOS DEL DISCURSO TURÍSTICO}

A continuación, trataremos brevemente los tres diferentes planos: pragmático, lingüístico y funcional, según la propuesta realizada por Durán Muñoz (2008, 2012), siguiendo los planos en los que Cabré Castellví (1993: 151) divide los lenguajes de especialidad, con objeto de compararla seguidamente con la características de un discurso turístico concreto, el relativo al turismo de aventura.

En primer lugar, nos encontramos con el plano pragmático. Siguiendo a Cabré Castellví (1993: 148-151), este plano viene determinado por tres aspectos fundamentales: la temática, los usuarios y la situación comunicativa.

En primer lugar, la temática caracteriza al discurso turístico en dos aspectos fundamentales: por un lado, en la variedad de segmentos turísticos que podemos encontrar según el tipo de turismo que se quiera realizar (turismo de sol y playa, turismo de aventura, turismo rural, turismo cultural, entre otros); y, por otro, en el abanico de disciplinas que se detectan en los textos turísticos, tales como la historia, la arquitectura, el deporte, la gastronomía y el arte.

Por su parte, la situación comunicativa y los usuarios dan lugar principalmente a tres niveles comunicativos dentro del sector turístico de tipo promocional:

La comunicación profesional especializada, que tiene lugar entre profesionales del sector, concretamente dentro de agencias de viajes, en la hostelería, en ferias y reuniones profesionales, etc.

La comunicación entre profesionales y usuarios o comunicación semiespecializada, que puede desarrollarse tanto de forma directa, en forma de 
conversaciones en agencias de viaje, hoteles y otras estructuras turísticas, interacciones con guías de turismo, etc., como indirecta, a través de medios electrónicos o escritos donde se presenta y describe el producto turístico.

La comunicación entre no especialista y no especialista, que comentábamos anteriormente y que está presente cada vez más en los entornos virtuales (Calvi y Bonomi, 2008). Esta comunicación divulgativa comparte algunos rasgos de la comunicación semiespecializada, concretamente con el uso de términos especializados del ámbito turístico, verbos en imperativo y recomendaciones, abundantes descripciones, función informativa y persuasiva del texto, aunque presentan una visión mucho más personal y más «real» del lugar que describen y, además, se trata de una comunicación personal y directa.

Un aspecto importante en este plano pragmático, que ha provocado la relegación del lenguaje del turismo a la lengua general y, por tanto, a la traducción general, es el predominio de comunicación especialista-usuario o de usuario-usuario. Este tipo de comunicación presenta una dificultad de comprensión menor que otras comunicaciones realizadas entre especialistas; sin embargo, el discurso turístico mantiene sus características esenciales de lenguaje de especialidad, incluso en este nivel de comunicación, debido a la presencia de terminología específica, sus funciones principales y sus rasgos lingüísticos propios.

Por lo que respecta al plano lingüístico, el discurso turístico se caracteriza principalmente por su terminología, que lo diferencia de otros lenguajes de especialidad. Como aspecto destacable en este plano, encontramos la heterogeneidad de las temáticas y de los diferentes segmentos turísticos, como veíamos anteriormente, que lo convierte en un lenguaje multidisciplinar, complejo y con gran riqueza de vocabulario.

A su vez, el lenguaje turístico presenta un elevado número de sinónimos o cuasisinónimos, como pueden ser los términos relacionados con el alojamiento (hotel, parador, hospedería, posada, hostal) ${ }^{7}$ con la designación de algunos segmentos turísticos (turismo alternativo, ecoturismo, turismo verde, turismo sostenible, etc.) o con servicios turísticos y actividades ofertadas (habitación con baño o habitación en suite). En muchos de estos casos, no es posible realizar un uso indiscriminado de esta variabilidad denominativa, ya que daría lugar a errores semánticos, como ocurre por ejemplo con los términos de alojamiento citados anteriormente. A pesar de ser alojamientos todos, cada uno denota una denota una realidad diferente, sujeta a unas características propias y diferentes de los demás.

En este lenguaje especializado, hay gran abundancia de términos culturales y una estrecha relación con las tradiciones locales (Calvi, 2006: 273), que son los llamados realia o culturemas, como por ejemplo pueblos blancos, costalero, almazara o sangría. Estas palabras poseen un valor semántico preciso pero pueden ser empleadas también con un significado valorativo, de acuerdo con las intenciones del texto, para beneficiarse de su trascendencia cultural como elemento de seducción. Los textos turísticos que tratan sobre gastronomía, arquitectura o alguna fiesta local presentan mayor número de términos

${ }^{7}$ En este caso, existe una clasificación de los establecimientos hoteleros basada en el Real Decreto 1634/1983 para los criterios generales, y en las leyes autonómicas para la definición de las distintas tipologías. 
culturales y, por tanto, anisomórficos con respecto a otras lenguas, ya que mantienen una estrecha relación con las tradiciones y la cultura local. Resulta obvia, por tanto, la dificultad de su traducción y la necesidad por parte de los traductores de prestar especial atención a este tipo de términos.

Otro aspecto esencial en este lenguaje especializado son los extranjerismos, especialmente los anglicismos, ya sea en modo de préstamos (charter, overbooking, trekking) o calcos (sobreventa, tiempo compartido, de bajo coste), debido al interés de los textos turísticos por mantener su carácter exótico, atractivo y, por supuesto, su función apelativa. Por el mismo motivo, se tiende a la innovación léxica y a los neologismos (agroturismo, turismo sostenible o ecovacaciones), derivado también del dinamismo terminológico característico de este discurso de especialidad (cfr. Durán Muñoz, 2014).

La utilización de recursos hiperbólicos de diferente naturaleza es también una práctica común (cfr. Bugnot, 2006), a saber: abundante presencia de comparativos y de superlativos, con lo que se le otorga al lenguaje una función apelativa y emotiva constante a la vez que se enfatizan las cualidades del producto. La promoción turística explota sistemáticamente esta estrategia y es muy usual en el lenguaje publicitario. El superlativo relativo es uno de los recursos más empleados, aunque a veces se encuentran formas atenuativas y la referencia resulta más genérica a la par que superlativos absolutos con el sufijo -ísimo (bellísimo, rarísimo, riquísimo). En los siguientes fragmentos, podemos observar varios ejemplos:

(1) Andalucía, es el principal destino vacacional de los españoles y uno de los principales para los extranjeros ${ }^{8}$.

Otra forma muy utilizada de expresar la singularidad consiste en utilizar adjetivos como único, auténtico, privilegiado, original, excelente, irrepetible, inolvidable u otras expresiones que niegan la existencia de parangones, así como el empleo verbos que indican la preeminencia dentro de un conjunto, como destacar o distinguirse y adverbios intensificadores, como extraordinariamente, intensamente $\mathrm{o}$ sorprendentemente. En los siguientes fragmentos, se pueden encontrar ejemplos de algunas de estas características:

(2) En los Parques Naturales de Grazalema y Sierra de las Nieves y Sierra Bermeja, hay bosques de pinsapos únicos en todo el mundo ${ }^{9}$

Finalmente, otra fórmula para intensificar el discurso son las denominadas afirmaciones categóricas y las tautologías (Bugnot, 2006: 31 y 33, respectivamente), como en el siguiente ejemplo:

(3) ... estilo artístico exótico y fascinante porque no se parece a nada de lo que puedan ver en sus lugares de origen ${ }^{10}$.

\footnotetext{
${ }^{8}$ En www.andalucia.org. El resaltado en negrita de todos los ejemplos no pertenece al original, están incluidos expresamente por la autora.

${ }^{9}$ En www.andalucia.org.
} 
(4) Asturias lo tiene todo ${ }^{11}$.

Con respecto a la sintaxis, hay ciertos aspectos del lenguaje del turismo que quedan caracterizados por este aspecto lingüístico.

En primer lugar, encontramos abundantes formas impersonales que buscan la despersonalización del mensaje, especialmente en catálogos y programas turísticos donde abunda el estilo nominal y las descripciones de lugares, personas, situaciones y servicios. Asimismo, las formas imperativas también adquieren gran importancia en determinados textos turísticos, como los anuncios y los folletos turísticos. No obstante, las formas personales, especialmente la primera persona del plural (nosotros) y las dos formas de la segunda persona (tú y usted) también se utilizan en este tipo de textos especializados, dependiendo estas últimas del grado de acercamiento que se desee imponer en el texto.

(5) Te invitamos a pasear por estos lugares emblemáticos y por tradiciones y ritos de contenido mágico y simbólico.

(6) Viaja a través del tiempo conociendo la Andalucía del pasado, del presente y del futuro. Sumérgete en un entramado de itinerarios cuyo trazado te descubrirá una tierra singular.

El tiempo verbal también es una peculiaridad de los textos turísticos, ya que predomina el presente de indicativo, aunque el pasado y el futuro también del indicativo también se encuentran en todo tipo de narraciones, pero en menor medida. Como hemos indicado, las descripciones son el principal discurso de los textos turísticos y, por tanto, el empleo de este tiempo verbal se ve condicionado a la presencia de estas descripciones. Se trata de un presente atemporal, que eterniza las peculiaridades y bellezas del lugar turístico, sea este monumento, paisaje o alojamiento. En el siguiente fragmento, se pueden observar varios ejemplos:

(7) La Jara es una bella comarca natural situada en una región de sierras, montes, dehesas, arroyos y ríos en la parte suroccidental de la provincia de Toledo, que se extiende sobre la cuenca meridional del río Tajo. La Jara posee una vegetación $[\ldots]^{12}$

Otro elemento sintáctico muy empleado en este tipo de textos son las oraciones condicionales y de relativo, que atenúan la fuerza prescriptiva y apelativa del mensaje a la par que ofrecen un abanico de posibilidades en función de los gustos y de las aficiones del potencial turista:

\footnotetext{
${ }^{10}$ En www.albalatedelarzobispo.com.

${ }^{11}$ En http://elpais.com/publi-especial/asturias.

12 Folleto turístico Provincia de Toledo, 2009. Instituto de promoción turística de Castilla-La Mancha.
} 
(8) Si lo que te gusta es disfrutar del paisaje y la naturaleza te sugerimos algunos lugares especiales por su belleza, por su entorno o por la diversión que ofrece al visitante $^{13}$.

Finalmente, es importante indicar otros rasgos característicos de este lenguaje especializado, como son el empleo frecuente de recursos estilísticos (como las metáforas, los símiles y las metonimias) con objeto de aportar belleza al texto y mantener su función poética y emotiva, como en los siguientes ejemplos:

(9) Un verdadero paraíso de emociones, sensaciones, recuerdos y experiencias donde es posible disfrutar de una naturaleza pura ${ }^{14}$.

(10) Déjate embrujar por dos ciudades repletas de historia ${ }^{15}$

En general, y para terminar con este plano lingüístico, podemos afirmar que se caracteriza por el predominio de la originalidad y la creatividad expresiva, la concisión y la brevedad, la connotación positiva y los eufemismos, los enunciados directos y descriptivos, así como la referencialidad y la preponderancia de los datos sensoriales, que procuran sumir al lector en las luces, colores, olores y ruidos del lugar evocado.

Por su parte, en lo que respecta al plano funcional, la función referencial y la función apelativa predominan claramente en el discurso turístico frente a otras funciones comunicativas (función expresiva o emotiva, función fática, función metalingüística y función poética), aunque estas se observan también en el discurso turístico en mayor o menor medida. Esta multifuncionalidad clara, sin embargo, viene determinada por jerarquía de funciones comunicativas, que dará lugar a una función prioritaria o predominante y a otras funciones secundarias. De esta manera, en el caso de los folletos turísticos, por ejemplo, su función predominante será la referencial, pero sus funciones secundarias serán la apelativa, la emotiva, la fática y la poética. En cambio, una guía turística tendrá también la función referencia y apelativa como principales pero no se le otorgará tanta importancia a la función fática o emotiva.

Una vez que hemos analizado brevemente las principales características del discurso turístico en general, nos centraremos ahora en aquellas que presenta el turismo de aventura, un segmento turístico en auge en la última década.

\section{EL TURISMO DE AVENTURA Y SUS CARACTERÍSTICAS PRAGMÁTICO-LINGÜÍSTICAS}

El turismo de aventura es uno de los segmentos de mayor crecimiento en el turismo en este momento, ya que cada vez más personas buscan vacaciones activas que combinen deporte, naturaleza y sostenibilidad. Se trata de una forma de turismo alternativo que consiste en la práctica de actividades de aventura de mayor a menor intensidad y riesgo al aire libre y en contacto con el medio natural. Aunque las actividades turísticas pasivas, especialmente relacionadas con el turismo de sol y playa, todavía ocupan una posición

\footnotetext{
${ }^{13}$ En www.lariojaturismo.com/rutas/index.php?Id contenido=18503.

${ }^{14} \mathrm{En}$ http://elpais.com/publi-especial/asturias.

${ }^{15}$ En www.jaenparaisointerior.es/tematicas/cultura/ubeda-y-baeza/presentacion.html.
} 
primordial en la economía mundial del turismo, varios tipos de turismo alternativo, como el que nos ocupa en este estudio, están ganando popularidad entre los turistas, lo que aumenta el volumen de ofertas de actividades, de paquetes turísticos, etc. más activos y alternativos. Este tipo de turismo, además, tiene una oferta muy amplia de actividades en diferentes medios naturales: tierra, agua, aire y actividades que combinan más de un elemento, como es el caso del barranquismo, que puede combinar tierra y agua. Por su parte, también ofrece diferentes niveles de dificultad y de riesgo, por lo que podemos encontrar actividades dirigidas a familias enteras o a personas mayores, como el senderismo suave, o actividades más demandantes como la escalada o el rafting. De esta manera, podemos considerarlo como un turismo que se adapta a las necesidades de los turistas y que potencia su actividad física según sus capacidades y sus intereses.

Debido al surgimiento relativamente reciente y al rápido desarrollo que ha tenido este segmento, no cuenta aún con una denominación específica y acordada por los expertos, ya que, como afirma Luque Gil (2003: 130), se usan indistintamente diferentes términos, a saber: turismo de aventura, turismo deportivo en la naturaleza, turismo activo-deportivo en la naturaleza, turismo activo y de aventura, turismo activo en la naturaleza, turismo deportivo y de aventura, entre otras, lo que provoca cierto desconcierto a la hora de utilizar y comprender el concepto. No obstante, a pesar de que estos términos se suelen utilizar de modo indiferente en numerosas ocasiones, la mayoría de los autores parecen decantarse por la utilización del término de turismo de aventura, aunque también encontramos otros que consideran el turismo activo como sinónimo de turismo de aventura (Aspas Aspas, 2000: 28) o, por el contrario, el turismo activo como un concepto de mayor alcance designativo que incluiría actividades consideradas «de aventura» y algunas otras que no contienen este rasgo al no entrañar o la emoción propios de las actividades de aventura (Estornell Pons, 2013: 35).

En España, los orígenes de estas actividades de aventura en la naturaleza se remontan a los años ochenta $\mathrm{y}$, desde entonces, su demanda ha estado en constante crecimiento. Debido a su reciente aparición, el turismo de aventura se considera un segmento turismo aún joven y poco consolidado, pero que poco a poco se está haciendo un hueco en el mercado turístico gracias al aumento de empresas que se dedican al turismo activo, a la presencia de estas empresas en Internet, a las subvenciones de las administraciones para mejorar infraestructuras, etc. En apenas un par de décadas, los deportes de aventura han dejado de considerarse especializados y orientados a grupos minoritarios de población para convertirse en una oferta cada vez más diversificada, adaptada y conectada con amplios segmentos de usuarios tanto nacionales como extranjeros (Rivera Mateos, 2007: 23).

Al igual que otros discursos especializados, el turismo de aventura presenta una serie de características pragmático-lingüísticas propias que lo diferencian de otros segmentos turísticos y que lo hacen particularmente interesante desde un punto de vista traductológico. A continuación, analizaremos un corpus comparable compuesto por textos promocionales en español sobre el turismo de aventura y trataremos de determinar si este tipo de discurso especializado mantiene las mismas características indicadas previamente para el discurso turístico en general o si, por el contrario, presenta algunos aspectos propios y diferenciadores. 


\subsection{Descripción del corpus}

La compilación de un corpus requiere la definición de un conjunto de variables en la fase de diseño de acuerdo con la finalidad del proyecto de investigación. En nuestro caso, se determinaron los criterios que aparecen a continuación, siguiendo a Bowker y Pearson (2002: 54).

\begin{tabular}{|l|l|}
\hline \multicolumn{1}{|c|}{ CRITERIO } & \multicolumn{1}{|c|}{ ESPECIFICACIÓN DEL CRITERIO } \\
\hline Criterio temporal & $\begin{array}{l}\text { La fecha de publicación o creación de los textos } \\
\text { seleccionados debe ser lo más reciente posible. }\end{array}$ \\
\hline Criterio geográfico & $\begin{array}{l}\text { Todos los textos seleccionados están delimitados } \\
\text { geográficamente, es decir, todos los textos en } \\
\text { español incluidos están escritos en la variedad de } \\
\text { español de España, con el fin de evitar la posible } \\
\text { variación terminológica diatópica, como podría } \\
\text { ocurrir si se utilizaran textos escritos en la variedad } \\
\text { de español de México o de Venezuela. }\end{array}$ \\
\hline Criterio formal & $\begin{array}{l}\text { Todos los textos están recogidos en su forma } \\
\text { completa y no como fragmentos o resúmenes de un } \\
\text { texto más amplio. }\end{array}$ \\
\hline Criterio de tipología textual & $\begin{array}{l}\text { Todos los textos seleccionados pertenecen al mismo } \\
\text { género, es decir, textos promocionales extraídos de } \\
\text { páginas webs de empresas de turismo activo, } \\
\text { agencias de viajes y de páginas institucionales } \\
\text { dirigidas a la promoción del turismo de aventura. }\end{array}$ \\
\hline Criterio pragmático & $\begin{array}{l}\text { Los textos seleccionados pertenecen a un entorno } \\
\text { comunicativo divulgativo o poco especializado, ya } \\
\text { que están escritos por especialistas pero dirigidos a } \\
\text { un público general con pocos conocimientos en el } \\
\text { ámbito científico y experto del turismo. }\end{array}$ \\
\hline Criterio de autoría & $\begin{array}{l}\text { Todos los textos son textos originales y auténticos, } \\
\text { no traducidos, elaborados por empresas o agencias } \\
\text { del sector y por instituciones públicas. }\end{array}$ \\
\hline
\end{tabular}

Tabla 1. Conjunto de criterios seguidos para la compilación del corpus

Estos criterios se determinaron inicialmente y sirvieron de guía durante la compilación del corpus con el fin de garantizar la homogeneidad y representatividad cualitativa del corpus. Los resultados cuantitativos de la compilación de este corpus comparable se recogen en la siguiente tabla.

\begin{tabular}{|c|c|c|}
\hline IDIOMA & $\begin{array}{c}\mathrm{N}^{\circ} \text { DE } \\
\text { DOCUMENTOS }\end{array}$ & $\begin{array}{c}\mathrm{N}^{\circ}{ }^{\circ} \mathrm{DE} \\
\text { TOKENS }\end{array}$ \\
\hline español & 455 & 252878 \\
\hline
\end{tabular}

Tabla 2. Datos cuantitativos del corpus comparable 
Una vez que se ha finalizado la compilación del corpus comparable en español, se inicia el análisis de los textos para detectar las características pragmático-lingüísticas descritas en la sección anterior en el discurso del turismo de aventura. Las principales herramientas que se utilizan para el análisis empírico han sido Termostat, utilizado para llevar a cabo la extracción automática de candidatos a términos, y AntConc, para buscar concordancias y expresiones formuladas. Por su parte, este estudio también ha requerido una aproximación manual de observación de los textos, puesto que muchas de las características analizadas no se podían detectar de forma automática.

\subsection{Plano pragmático y funcional en el turismo de aventura}

El plano pragmático de este tipo de turismo con relación a los textos promocionales está dividido también en las tres situaciones comunicativas diferentes, a saber: 1) comunicación experto-experto, 2) comunicación experto-usuario (o turista), y 3) comunicación de usuario-usuario (turista-turista).

Las dos primeras situaciones funcionan de la misma manera que en el discurso turístico en general; sin embargo, con respecto a la tercera situación comunicativa, se encuentran aún pocos foros donde los usuarios tratan este tipo de turismo. No obstante, conforme se va asentando en la sociedad española van apareciendo nuevas formas de comunicación en Internet y, por tanto, surgen nuevos entornos virtuales donde los usuarios/turistas dan su opinión, ofrecen recomendaciones y muestran sus quejas sobre servicios y productos turísticos relacionados con las actividades de aventura. Ejemplos de esto los encontramos en la página web de Senderoxtrem o de Foro MTB ${ }^{16}$, dos foros dedicados al senderismo en general donde los usuarios ofrecen recomendaciones de material, de rutas y de servicios relacionados con el senderismo y actividades afines.

Respecto a las funciones comunicativas, los textos turísticos relacionados con el turismo de aventura mantienen también las funciones referencial y apelativa como prioritarias, aunque utilizan a menudo la función emotiva y fática para atraer al turista y despertarle el interés por las vacaciones activas. La función poética, por su parte, ocupa también un lugar importante en la mayoría de textos pero inferior si lo comparamos con otros textos turísticos promocionales. Esto se debe principalmente a la presencia frecuente de definiciones, descripciones, recomendaciones y normas de uso relativas a la práctica de las actividades de aventura, del equipamiento y del uso de las zonas naturales donde se practican que no son frecuentes en otros segmentos como el turismo cultural, de sol y playa o gastronómico. En el siguiente ejemplo, observamos claramente la función referencial así como la función apelativa y fática, con esa pregunta retórica dentro del párrafo, que pretende atraer al turista y conseguir una respuesta positiva y activa por su parte. En cambio, la función emotiva y, especialmente, la poética no resultan muy marcadas.

(11) Te propongo un plan que combine naturaleza, bellos paisajes y un toque de aventura a ritmo galope. ¿Apetece? Si es así aquí os presentamos una de las alternativas y

\footnotetext{
${ }^{16}$ En www.senderoxtrem.com/foro/index.php y www.foromtb.com, respectivamente.
} 
cosas que hacer en la Sierra de Aracena más recomendables: un paseo en caballo por alguno de los muchos y variados senderos de nuestra sierra ${ }^{17}$.

Junto a este texto aparecen varias fotos evocadoras que aumentan el interés del turista para realizar este tipo de actividad. En este sentido, al igual que ocurre en el discurso turístico en general, en el turismo de aventura el material icónico es esencial para captar la atención del turista y conseguir atraer su interés.

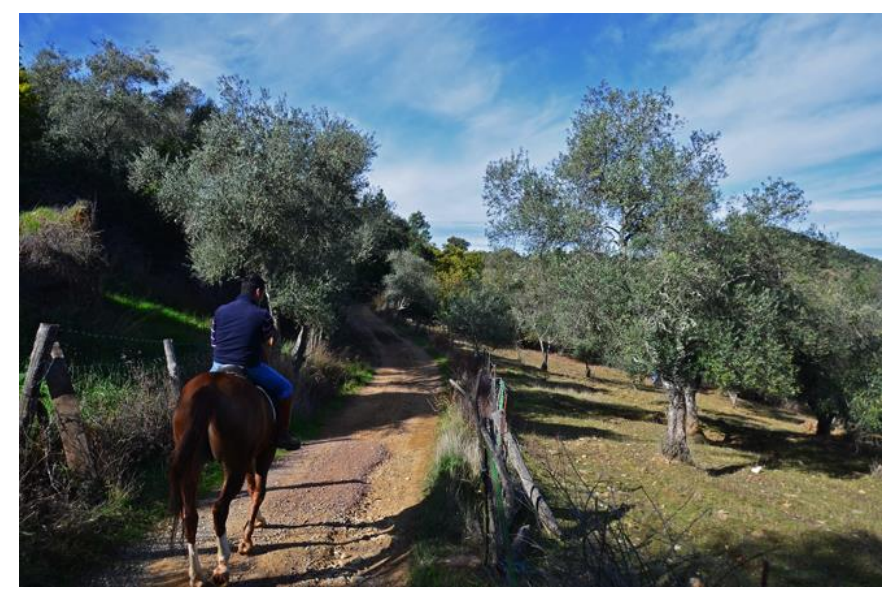

Fuente: Página web de Andalucía.org

\subsection{Plano lingüístico en el turismo de aventura}

Al igual que los textos turísticos en general, los textos promocionales sobre el turismo de aventura están caracterizados por su terminología, su sintaxis, su estilo y sus recursos estilísticos. En general, podemos decir que no se detectan grandes diferencias con el resto de textos turísticos referentes a otros segmentos, ya que hacen uso de la connotación positiva en diferentes categorías gramaticales (verbos, adjetivos, sustantivos y adverbios), de comparativos y superlativos, concisión, originalidad, entre otros, pero también cuentan con unas características propias que lo distinguen de otros segmentos turísticos como pueden ser el segmento turístico de sol y playa o de idiomas. En este apartado, expondremos una descripción de los principales aspectos lingüísticos que presenta de acuerdo con un análisis basado en el corpus analizado compuesto por textos promocionales en español sobre este tipo de turismo.

En el nivel léxico, se puede observar claramente cómo se delimita este segmento turístico y se diferencia del discurso turístico en general y de otros segmentos turísticos. En este tipo de turismo, las actividades de aventura son los productos principales y, como tales, marcan la terminología de este segmento. Asimismo, las personas que participan en ellas -ya sean turistas, agencias, monitores o guías- son un pilar esencial, junto con el lugar y el material que se necesita para ponerlas en práctica. Además de esta terminología, podemos encontrar también referencias a alojamientos, transportes, gastronomía y otras realidades turísticas, aunque en menor medida. Tanto es así, que la

\footnotetext{
${ }^{17}$ En www.andalucia.org/es/reportajes/a-caballo-por-la-sierra-de-aracena.
} 
mayoría de los textos promocionales están divididos por actividades de aventura e incluyen información relativa a dichas actividades. Siguiendo un estudio previo (Durán Muñoz, 2013), se pueden distinguir claramente las cuatro categorías semánticas siguientes en el turismo de aventura, ya que aparecen normalmente en cualquier texto promocional sobre este tema, a saber:

\section{Participante;}

2. Actividad que se realiza;

3. Lugar donde se realiza, y

4. Material necesario para la actividad.

En el siguiente texto, extraído de la página web de Andalucia.org, podemos observar estas cuatro categorías semánticas:

\section{Kayak y rafting por el Genil en Écija}

Siente la adrenalina más refrescante de la provincia de Sevilla con este emocionante reportaje por las aguas del rio Genil a su paso por Écija.

Leer en una misma frase las palabras «rafting, agua y Sevilla» puede dejarte cuanto menos, extrañado, ¿no es así? Y es que apostamos que muchos de vosotros desconocíais por completo que en pleno corazón de la provincia de Sevilla, se puede disfrutar de los rápidos del Rio Genil a su paso por Écija tanto kayak como en rafting.

De la mano de la empresa Saltarios, empresa de turismo activo que realiza actividades por toda Andalucía, nos ataviamos de neoprenos, cascos y escarpines...

Y comenzamos el descenso del río Genil, en un principio por preciosos tramos rodeados de vegetación y relajantes aguas.

Y del relax... pasamos a la acción con algunos rápidos tan divertidos como estos donde sentir la fuerza del agua y sufrir una buena descarga de estrés!

\section{¿Kayak o rafting?}

Si te decides por probar las aguas del río Genil tendrás 2 opciones a cual más divertida. Por un lado el kayak, bien de uso doble o individual, con el que personalmente te diremos que la bravura del agua se percibe muchísimo.

Los vaivenes de las corrientes te hacen más partícipe del medio en el que te encuentras y la sensación de velocidad es mucho mayor.

Y por otro lado, el rafting. La clásica lancha grande para 5-8 personas en la que tan sólo deberéis obedecer las órdenes de remado de vuestro guía y donde el trabajo en equipo es fundamental a la hora de avanzar.

Esta opción es ideal para grupos de amigos y la diversión, risas y por supuesto adrenalina, ¡están garantizadas! ${ }^{18}$

\footnotetext{
${ }^{18}$ En www.andalucia.org/es/reportajes/kayak-y-rafting-por-el-genil-en-ecija.
} 
En este breve texto, observamos la descripción de una actividad de aventura, el rafting, con una fuerte función referencial y apelativa, y las principales categorías semánticas que caracterizan a este tipo de turismo, a saber:

1. Participante: guía, empresa Saltarios, tú (turista), grupo de amigos.

2. Actividad que se realiza: kayak, rafting, descenso de río.

3. Lugar donde se realiza: río Genil, Écija, Sevilla, rápidos, corrientes.

4. Material: neoprenos, cascos, escarpines, kayak, lancha, rafting.

En este mismo texto se observa también una fuerte carga apelativa a través de adjetivos, sustantivos y verbos de movimiento, de acción y de sentimientos. En el caso de los verbos, encontramos sentir, desconocer, disfrutar, pasar a la acción, sufrir, decidir, percibir y encontrar, con el objetivo de ejercer gran influencia en el receptor del texto. Por su parte, los adjetivos utilizados se dirigen principalmente a calificar las sensaciones de los practicantes y de la actividad, tales como refrescante, emocionante, extrañado, preciosos, relajantes, divertidos y divertida e ideal, mostrando así abundantes connotaciones positivas y relacionadas con una actividad física. Finalmente, muchos de los sustantivos utilizados también marcan el objetivo de la actividad y de las sensaciones vividas con el uso de adrenalina en dos ocasiones, relax, descarga de estrés, bravura, sensación y partícipe. Este tipo de adjetivos, sustantivos y verbos con gran carga apelativa no solo los podemos encontrar en este texto, sino que son comunes en todos los textos promocionales del turismo de aventura. De esta manera, encontramos, además de los anteriormente citados, otros muchos ejemplos:

- Adjetivos: privilegiado, perfecto, increíble, inolvidable, incomparable, espectacular, singular, impresionante, exclusivo, mágico, etc.

- Sustantivos: aventura, maravilla, experiencia, paraíso, emoción, etc.

- Verbos: superar, experimentar, probar, atreverse, vivir a tope, no poder dejar de, etc.

- Adverbios: tremendamente, sumamente, etc.

A este punto podemos confirmar que el léxico empleado en el texto analizado ejemplifica claramente el léxico propio de este tipo de turismo, que lo diferencia de otros turismos donde impera más la relajación, la belleza, la calma, entre otros objetivos. Como hemos visto, en el turismo de aventura lo más importante es sentir, vivir, superar emociones y retos personales, combinando una actividad física adaptada al nivel de cada uno en plena naturaleza, y su vocabulario sigue claramente estas prioridades.

Otro aspecto característico de este tipo de turismo son los extranjerismos, principalmente los anglicismos. En este texto tomado como ejemplo, encontramos los términos kayak y rafting únicamente, pero es frecuente el uso de estas unidades. Al igual que ocurre con los discursos de otros segmentos turísticos, los extranjerismos, en forma de calcos o de préstamos, aparecen frecuentemente en los textos promocionales en busca del exotismo, del atractivo, de la novedad y de la originalidad para atraer a los turistas potenciales. Sin embargo, en el caso del turismo de aventura los textos 
promocionales están inundados de estos términos al mantener el nombre de la actividad de aventura en su forma original, normalmente de origen anglosajón, tales como rafting, paintball, mountain bike, team building, mushing, boulder, nordic walking o snorkel, así como préstamos adaptados a la lengua española como hidrospeed, surfista, camping o windsurfista. Entre estas actividades, también encontramos, aunque en menor medida, términos procedentes de otras lenguas, como del francés: rápel (o rappel), arnés o parapente; del italiano: tirolina, o del alemán: abseiling.

Como decíamos anteriormente, el número de extranjerismos, ya sean en forma de calcos o de préstamos, es muy elevado en este tipo de turismo, ya que, incluso cuando encontramos equivalentes de traducción en español, se tiende a utilizar el término extranjero, con objeto de aumentar su exotismo y su atractivo a la vista de turistas potenciales y, por tanto, mantener la función apelativa del texto. De esta forma, incluso cuando se cuenta con traducciones aceptadas en la lengua española, como en el caso de mushing con trineo de perros, hydrobob con hidrobob, rappel con rápel, se impone a menudo el término no adaptado.

La consecuencia inmediata de esta realidad es la gran variabilidad denominativa que encontramos en este tipo de discurso, ya que existe una alta convivencia de términos extranjeros con términos españoles con un uso poco o nada normalizado o al menos armonizado ( $c f r$. Durán Muñoz, 2014). De esta manera, encontramos actividades que se refieren, por ejemplo, como mountain bike y bicicleta de montaña o trekking y senderismo en diferentes textos promocionales. Además, se detecta también una alta frecuencia de sinónimos o cuasisinónimos, tanto de origen español (alpinismo y montañismo, barranquismo y descenso de barrancos) como de origen extranjero (flysurf y kitesurf, esquí acuático y esquí náutico) y de variaciones formales de las unidades (wind surf y windsurf o wake board y wakeboard). Finalmente, se observa también con frecuencias términos con apariencia extranjera pero creados directamente en lengua española, como ocurre con el término puenting o canoping, así como variantes léxicas en la propia lengua española, como, por ejemplo, las construcciones rutas en vehículo todo terreno (también con la siguiente variación: todoterreno o todoterreno), itinerarios $4 X 4$, rutas en vehículo $4 X 4$, rutas todo terreno (todoterreno o todoterreno), entre otras opciones.

La utilización de extranjerismos en una lengua es una forma de creación de unidades léxicas (o neologismos), un aspecto muy característico de este tipo de turismo como hemos visto. A su vez, la creación directa de unidades así como la ampliación o modificación semántica de unidades existentes es también una técnica extendida en este discurso y una prueba de su alto dinamismo conceptual, provocadas principalmente por dos motivos: por un lado, porque aparecen continuamente nuevas actividades del turismo de aventura que no existían, como el zorbing o el paddle surf, o actividades variantes de las existentes, como el aquaseiling (unidad derivada de la actividad de abseiling), a fin de ofrecer nuevas experiencias y oportunidades a los usuarios más intrépidos; por otro lado, porque se emplean para despertar el interés de los turistas con ofertas exóticas y novedosas, algo característico del discurso del turismo como veíamos.

Otro aspecto importante del discurso turístico y, en parte, también de este segmento son los llamados realia o culturemas, es decir, conceptos propios de una 
cultura que no existen en otra y que están cargados de connotaciones culturales. En este caso, encontramos gran cantidad de este tipo de unidades relacionadas con los paisajes y con los espacios protegidos. Por ejemplo, observamos numerosos términos para definir diferentes caminos de montaña como vereda, vía pecuaria, sendero, calzada o cañada real, cuya diferenciación está sujeta a tradiciones y a legislación concreta que no existe en otros países o variedades del español; para nominar la vegetación y la fauna autóctona de una zona; para hacer referencia a zonas protegidas, como parque nacional, parque natural o reserva natural, que se diferencian en función de la legislación nacional o autonómica correspondiente, entre otras muchas realidades.

Alejándonos ahora del aspecto léxico del turismo de aventura y aproximándonos a la sintaxis de este tipo de turismo, observamos similitudes con el discurso turístico en general. Este es el caso, por ejemplo, del uso abundante de comparativos y de superlativos, siendo el superlativo relativo uno de los recursos más empleados. Como ocurría en el discurso turístico en general, los comparativos y superlativos son una forma de equiparar el producto o servicio turístico a otros similares y destacar sus ventajas y sus características más positivas. De esta manera, se atrae la atención de los turistas potenciales y se despierta su interés de forma exponencial. Los siguientes son ejemplos extraídos del corpus utilizado:

(12) El cerro Alcojona se yergue sobre La Nava y en sus laderas crece el más vigoroso pinsapar del parque natural.

(13) Probablemente el río más divertido del Sur de España, a tu alcance de la mano de nuestros guías.

(14) Unos de los cañones más espectaculares de Andalucía.

(15) No existe una región española con más días de sol durante todo el año.

En esta misma línea, encontramos también combinaciones de sustantivo + adjetivo que aportan gran fuerza al texto a la par que singularidad y prestigio. Se podrían considerar incluso como superlativos absolutos desde un punto de vista semántico. Ejemplos de estas combinaciones son las siguientes: destino privilegiado o destino perfecto, magníficas condiciones climáticas, gentes inigualables, increíble valle, experiencia inolvidable, marco incomparable, posición privilegiada, entre otros muchos ejemplos.

Similar también a lo que ocurría en el discurso general, encontramos numerosos ejemplos del uso de la primera persona del plural (nosotros) y de las dos formas de la segunda persona (tú y usted), aunque especialmente de la forma tú. Este tipo de turismo se decanta por un trato informal y cercano, dirigiéndose directamente al lector e intentando despertarle siempre al potencial turista su interés por el servicio o producto que está promocionando. En los siguientes ejemplos se observa claramente este trato directo y cercano.

(16) Te acercaremos a paisajes de ensueño, conocerás la flora y fauna de nuestra zona, garantizamos la emoción y el riesgo con la máxima seguridad para los más aventureros. 
(17) Nuestro centro te permite descubrir el entorno del Parque Natural del Estrecho para respetarlo y disfrutarlo mejor.

Por su parte, son frecuentes también las formas impersonales, que hablan de forma general, especialmente en lo que respecta a las descripciones de actividades, de lugares y de servicios relacionados con las actividades de aventura; y los imperativos, que pretenden atraer a los turistas potenciales con un lenguaje directo.

(18) Es necesario utilizar arnés, cuerdas, mosquetones, cabos de anclaje y descensor, para controlar la velocidad y la seguridad en el descenso.

(19) Se organizan salidas para principiantes y avanzados.

(20) Disfruta, aprende y descubre tus habilidades durante tu iniciación.

(21) Ven y disfruta con los tuyos de una ruta maravillosamente fácil.

El tiempo verbal predominante es el presente de indicativo, al igual que en el discurso turístico en general, ya que las descripciones son las principales fuentes de información. Sin embargo, también encontramos el empleo del futuro simple cuando se hace referencia a la experiencia que tendrá el turista cuando esté realizando la actividad de aventura concreta, como ocurre, por ejemplo, en el siguiente ejemplo:

(22) Te aconsejamos ir acompañado de un guía que conozca el terreno sobre el que iniciarás la aventura, al menos hasta que tengas la experiencia y los

Las oraciones subordinadas, especialmente las condicionales, también se utilizan frecuentemente en este tipo de discursos a modo de apelación al turista para que realice la actividad.

(23) Si desea pasar una inolvidable jornada de pesca, no dude en consultar nuestras ofertas.

(24) Si buscas el edén del windsurf, tendrás que elegir Tarifa (Cádiz) y sus alrededores, puntos de encuentro de windsurfistas de toda Europa.

Al igual que ocurría también con el discurso turístico en general, cabe destacar aquí también el uso frecuente de recursos estilísticos, como las metáforas, las personificaciones, las hipérboles y las metonimias, con objeto de aportar belleza al texto $\mathrm{y}$ tocar emotivamente al lector.

(25) ALA DELTA: Un paraíso para los pájaros con alas de tela.

(26) Andalucía es una gran enamorada del mar.

(27) La magestuosidad de la boca de gato nos invita a sumergirnos en su misterio.

\section{CONCLUSIONES}

Tras el análisis llevado a cabo en las secciones precedentes, podemos afirmar que, en estos textos promocionales sobre el turismo de aventura, predomina la originalidad, 
la brevedad, el trato directo con el turista y la connotación positiva, todo ello, al igual que ocurría con el discurso turístico en general, con el objetivo de atraer a los turistas potenciales para que practiquen las diferentes actividades de aventura y disfruten de la naturaleza. Por su parte, tampoco se ha observado gran diferencia en el aspecto pragmático y funcional de los textos promocionales que versan sobre este tipo de turismo en comparación con otros turismos.

No obstante, este tipo de turismo marca una diferenciación clara con otros segmentos turísticos principalmente a través de su terminología y de su léxico, ya que predomina la llamada a la acción, al movimiento, al desafío y a la consecución de retos por parte de los turistas a través de adjetivos, sustantivos, adverbios y verbos perfectamente elegidos. También se detecta un mayor número de extranjerismos, bien en forma de calcos o de préstamos, debido principalmente a la aparición de este tipo de actividades de aventura fuera de España (especialmente en el ámbito anglosajón) además de a la búsqueda del exotismo y de la atracción constante del potencial turista. La variación denominativa y el alto dinamismo terminológico es la tónica más frecuente también en estos textos promocionales, provocada por la convivencia de extranjerismos y sus equivalentes en español, y por la rápida aparición de estas actividades en la oferta turística por parte de las empresas y agencias sin una previa regulación o armonización de su terminología.

Esta aproximación al aspecto pragmático-lingüístico y funcional del discurso del turismo de aventura ha pretendido describir sus principales características y ofrecer una visión general, con objeto de promover el estudio de este segmento turístico en futuros trabajos, especialmente en el plano léxico, y de apuntar las principales dificultades de este discurso a los traductores de este tipo de textos turísticos. A través del análisis ofrecido, podemos confirmar que se trata de un tipo de discurso muy complejo y dinámico, cuya terminología se encuentra en constante cambio y crecimiento en consonancia con la aparición de nuevas actividades de aventura, y que presenta una serie de características propias que lo alejan de otros segmentos turísticos, como podrían ser el turismo de salud y belleza o el turismo cultural.

\section{REFERENCIAS BIBLIOGRÁFICAS}

ASPas ASPAS, José María (2000): Los deportes de aventura. Consideraciones jurídicas sobre el turismo activo, Santa Cruz de Tenerife, Prames.

BOWKER, Lynne y Jennifer PEARSON (2002): Working with Specialized Language:

A practical guide to using corpora, Londres, Routledge, <http://dx.doi.org/10.4324/9780203469255>:

Brosson, Frédéric (2008): Contenu du module «Le Français du Tourisme», Agence universitaire de la Francophonie [en línea]: <http://fromulus.chezalice.fr/documents/tourisme.pdf>. [Consulta: 12/10/2014].

Cabré CAstellví, M. ${ }^{a}$ Teresa (1993): La terminología. Teoría, metodología, aplicaciones, Barcelona, Antártida/Empúries. 
Cabré Castellví, M. ${ }^{a}$ Teresa (2002): «Textos especializados y unidades de conocimiento: metodología y tipologización», en García, J. y M. T. Fuentes, eds., Texto, terminología y traducción, Barcelona, Almar, 122-187.

CABré Castellví, M. ${ }^{a}$ Teresa (2006): «La clasificación de neologismos: una tarea compleja», Alfa: revista de lingüística, 50(2), São José do Rio Preto, Universidade Estadual Paulista, 229-250.

CAlvi, M. ${ }^{a}$ Vittoria (2000): El léxico del turismo. Universidad de Bérgamo [en línea]: 〈http://www.ub.es/filhis/culturele/turismo.html>. [Consulta: 12/10/2014].

CALVI, M. ${ }^{a}$ Vittoria (2010): «Los géneros discursivos en la lengua del turismo: una propuesta de clasificación», Ibérica: Revista de la Asociación Europea de Lenguas para Fines Específicos (AELFE), 19, 9-32 [en línea]: <http://www.aelfe.org/documents/01_19_Calvi.pdf $>$.

CAlvi, M. ${ }^{a}$ Vittoria (2011): «El lenguaje del turismo», en Calvi, M. V., C. Bordonaba Zabalza, G. Mapelli y J. Santos López, eds., Las lenguas de especialidad en español, Roma, Carocci editore, 199-224.

CALVI, M. ${ }^{a}$ Vittoria (2006): «El uso de términos culturales en el lenguaje del turismo: los hoteles y su descripción», en Calvi, M. ${ }^{a}$ V. y L. Chiexichetti, Nuevas tendencias en el discurso de especialidad, Berna, Peter Lang, 271-292.

CALVI, M. ${ }^{a}$ Vittoria y Milin BonOMI (2008): «El lenguaje del turismo: de los textos especializados a la Comunidad del viajero», en Navarro, C., R. M. Rodríguez Abella, F. dalle Pezze y R. Miotti, eds., La comunicación especializada, Berlín, Peter Lang, 181-202.

CALVI, M. ${ }^{a}$ Vittoria (2014): «Guía de viaje y turismo 2.0: los borrosos confines de un género», Conferencia inaugural del Simposio Internacional Discurso y Géneros del Turismo 2.0, Universitat de València, 2-4 de abril de 2014.

DanN, Graham (1996): The language of Tourism. A Sociolinguistic Perspective, Oxon, CAB International.

DANN, Graham (2007): «Revisiting the language of tourism: what tourists and tourees are saying», en De Stasio C. y O. Palusci, eds., The Language of Tourism. Turismo e Mediazione, Milán, Unicopli, 15-32.

DURÁN MUÑOZ, Isabel (2008). «La necesidad de profesionalización en la traducción turística», I Congreso Internacional Translation in the Era of Information. Oviedo, 22-24 de octubre de 2008.

DURÁN MUÑOZ, Isabel (2012): «Necesidades de mejora y adecuación en la traducción de textos turísticos promocionales», Hermeneus, 14, 264-277.

DURÁN MUÑOZ, Isabel (2013): «El turismo de aventura en textos promocionales y su terminología», en Candel Mora, M. Á., ed., El lenguaje del turismo y la publicidad: terminología y traducción, Barcelona, Wolters Kluwer, 251-277.

DURÁn MuÑOZ, Isabel (2014): «Cross-domain disharmonization. A case study with adventure activities in legal and tourist domains in Spain», en Temmerman, R. y M. van Campenhoudt, eds., The dynamics of culture-bound terminology in monolingual and multilingual communication, Series Terminology and Research and Practice, Ámsterdam/Filadelfia, John Benjamins, 79-98. 
ESTORnell Pons, María (2013): «Aproximación al léxico del turismo activo: codificación lexicográfica, formación y variación denominativa», Normas. Revista de estudios lingüísticos hispánicos, 3, 33-55.

KELLY, Dorothy (1997): «The translation of texts from the tourist sector: textual conventions, cultural distance and other contrainsts», TRANS, 2, 33-42.

LUQUe GIL, Ana M. ${ }^{a}$ (2003): Las actividades recreativo-deportivas y el uso turístico del medio natural, tesis doctoral, Málaga, Servicio de Publicaciones de la Universidad de Málaga.

Ministerio De Industria, Turismo y COMERCIO. 2013. Informe Anual 2012. Encuesta de Gasto Turístico (Egatur) [en línea]: <http://www.iet.tourspain.es/esES/estadisticas/egatur/Anuales/Movimientos\%20Tur\%C3\%ADsticos\%20en\%20Fronter as $\% 20 \% 28$ Frontur\%29\%20y\%20Encuesta\%20de\%20Gasto\%20Tur\%C3\%ADstico\%20 \%28Egatur\%29\%202012.pdf>. [Consulta: 12/10/2014].

REISS, Katharina y Hans J. VERMEER (1991): Grundlegung einer allgemeine Translationstheorie, Tubinga, Max Niemeyer Verlag.

RIVERA MATEOS, Manuel (2007): «La emergencia del turismo y el ocio deportivo en la naturaleza en Andalucía y España: aproximación al estudio de su demanda reciente», Actas de las I Jornadas sobre Turismo y Sociedad en Andalucía, Instituto de Estudios Sociales Avanzados (IESA-CSIC), Córdoba, 1-26.

SANMARTín SÁEZ, Julia, ed. (2012): Discurso turístico e Internet, Madrid/Frankfurt, Iberoamericana Vervuert (colección: Lingüística Iberoamericana, 48). 